\title{
PERANCANGAN ENSIKLOPEDIA MEXOLIE: SUATU PENDIDIKAN SEJARAH AGRARIA DI KEBUMEN
}

\author{
${ }^{1}$ Azhari Amri, ${ }^{2}$ Sri Sulastri, ${ }^{3}$ Huddy Husin \\ Universitas Indraprasta PGRI \\ Jl. Nangka No.58 Tanjung Barat, JakartaSelatan, Indonesia \\ lazhariamri86@gmail.com; ${ }^{2}$ srisulastri@gmail.com; ${ }^{3}$ hudi0212@gmail.com
}

\begin{abstract}
Abstrak
Saat ini, desain komunikasi visual telah berelasi dengan bidang studi lain, peran ini dipilih untuk mampu menciptakan media sebagai ujung tombak komunikasi yang dinamis dari substansi bidang studi lain. Atas dasar itu, penelitian ini menempatkan bidang studi Sejarah sebagai rekan dalam upaya kolaborasi bidang studi. Penelitian ini mengambil satu wilayah dari 9 (sembilan) sentra sejarah industri minyak kelapa di Hindia-Belanda yaitu Pabrik Mexolie di Kebumen. Memasuki akhir abad ke-19 tanaman kelapa menjadi primadona dalam perdagangan internasional, dimana selain sebagai bahan baku utama dalam membuat minyak goreng, tanaman kelapa juga dapat menjadi bahan baku lainnya seperti entega, sabun dan bahan obat-obatan. Dengan kolaborasi sejarah struktural pada aspek sosio-kultural yang dikawinkan dengan penciptaan proses kreasi melalui buku ensklopedia telah menempatkan suatu penyajian penulisan sejarah berkesan modernis dan ringan. Hal ini dilakukan untuk mampu memuseumkan arsip dokumen sejarah sebagai media belajar, agar mudah menarik perhatian generasi muda khususnya. Melalui usaha penciptaan ensiklopedia yang dibarengi dengan pengkajian lebih mendalam mengenai insudtrialisasi minyak kelapa ini, kita dapat memahami mengapa perkembangan kehidupan ekonomi masyarakat Kebumen saat ini, sudah tidak lagi menghidupkan industri minyak kelapa sebagai ujung tombak ekonomi agraria
\end{abstract}

Kata kunci: Desain, Sejarah, Mexolie, Kebumen

\section{MEXOLIE ENCYCLOPEDIA DESIGN: AN AGRARIA HISTORICAL EDUCATION IN KEBUMEN}

\begin{abstract}
Currently, visual communication design has been related to other fields of study, this role is chosen to be able to create media as the spearhead of dynamic communication from the substance of other fields of study. On this basis, this research puts the field of study of History as a partner in the collaborative effort of the field of study. This study takes one area of the 9 (nine) historic coconut industry center in the Dutch East Indies, the Mexolie Factory in Kebumen. Entering the late 19th century coconut plants became a prima donna in international trade, where in addition as the main raw material in making cooking oil, coconut plants can also be other raw materials such as enthal, soap and medicinal materials. With the structural history collaboration on the socio-cultural aspects mated to the creation of the creation process through the encyclopedia book has placed a presentation of modernist and lightweight memorable historical writing. This is done to be able to memuseumkan archives of historical documents as a medium of learning, in order to easily attract the attention of young people in particular. Through the creation of an encyclopedia coupled with a deeper examination of the insti-tropisation of coconut oil, we can understand why the development of economic life of Kebumen society today, no longer turn the palm oil industry as the spearhead of the agrarian economy.
\end{abstract}

Key Words: Design, History, Mexolie, Kebumen 


\section{PENDAHULUAN}

Penelitian ini akan mengambil satu wilayah dari 9 (sembilan) sentra industri minyak kelapa yang ada di HindiaBelanda, dengan pertimbangan ketersedian sumber dan ketersedian penelitian yang pernah melakukan penelitian sejarah minyak kelapa di Hindia-Belanda. Perkebunan dan pabrik minyak kelapa di Kebumen merupakan pilihan wilayah penelitian yang ditetapkan oleh tim peneliti, mengingat ketersedian sumber dan adat penelitian yang cukup, serta sepemahaman penulis, belum ada penelitian yang menempatkan atau mengkaji mengenai industri minyak kelapa di wilayah Kebumen.

Kebumen sejatinya dalam sejarah Jawa, merupakan salah satu wilayah yang dikuasai oleh Kerajaan Mataram. Sebagai sebuah wilayah yang secara umum memiliki kontur geografis berupa dataran rendah, Kebumen memiliki potensi untuk membangun kekuatan ekonomi yang berbasiskan ekonomi agraria. Berdasarkan keadaan ekologi tersebut, maka tidak terlalu mengherankan jika kemudian banyak ditemui pusat-pusat pertanian dan perkebunan dihampir seluruh wilayah Kebumen (seperti sawah dan ladang perkebunan). Berkuasanya pemerintah kolonial Hindia-Belanda (sebelumnya VOC), membuat wilayah Kebumen, tidak hanya diposisikan sebagai wilayah penghasil Beras saja, akan tetapi juga didorong untuk dapat menopang kebijakan dagang pemerintah kolonial, melalui pembangunan industri kelapanya.

Pembangunan industri minyak kelapa di Kebumen dibuka sejak tahun 1851, pabrik tersebut dikelola oleh pemrintah kolonial Hindia-Belanda dan diberi nama Oliefabrieken Insulinde Keboemen. Pabrik minyak kelapa tersebut dikelola oleh pemerintah HindiaBelanda hingga tahun 1923, dimana kemudian diberikan kepada pihak swasta untuk dikelola. Perubahan pengeloalaan pabrik minyak kelapa tersebut membawa perubahan pula nama pabrik tersebut, yakni NV. Mexolie Keboemen. Perusahaan NV. Mexolie Keboemen inilah yang kelak mengelola aktivitas olah industri minyak kelapa di wilayah Kebumen hingga masa akhir penguasaan HindiaBelanda di Indonesia (Paper Kerja oleh Yayasan Wahyu Pancasila, dipublikasikan di seminar keluarga besar eks karyawan Pabrik Minyak Kelapa Kebumen, pada 31 Mei 2015).

Begitu banyak dinamika yang berjalan berupa pasang-surut dan naik turunnya pengelolaan industri minyak kelapa di Kebumen ini, khususnya pada masa-masa krisis ekonomi tahun 1930, hingga adaptasi pengelolaan dari pemerintah menuju pihak swasta, dan lain sebagainya. Hal inilah yang dianggap sangat menarik untuk dikaji oleh tim peneliti, melalui pendekatan sejarah ekonomi ditingkat lokal Kebumen.

Dengan menempatkan pendekatan proses perancangan yang ada dalam desain komunikasi visual, diharapkan terciptanya suatu model karya desain yang berdekatan dengan tujuan pendidikan Sejarah yaitu menyajikan informasi sejarah yang dapat didiseminasikan dan dipelajari oleh banyak pihak melalui gaya infografis berupa Ensiklopedia Rekonstruksi Sejarah.

\section{Metode Penelitian}

Metodologi yang akan digunakan dalam penelitian ini ialah model penelitian kualitatif dengan dua pendekatan yaitu pendekatan sejarah struktural pada bidang studi penelitian sejarah, kedua adalah pendekatan perancangan (model visual) sebagai ciri dari bidang studi desain komunikasi visual.

Kajian analisis sejarah struktural ditegaskan oleh Sartono Kartodirjo (1992: 146), bahwa sejarah analitis dan sejarah struktural hanya dapat dikaji dan 
ditulis dengan baik apabila pendekatan sosiologis khususnya dan pendekatan ilmu sosial pada umumnya diterapkan. Dengan perkembangan jenis-jenis sejarah tersebut kesempatan luas bagi pertumbuhan pelbagai ragam sejarah baru, antara lain (1) sejarah politik gaya baru; (2) sejarah sosial; (3) sejarah sosiologis; (4) sosiologi sejarah; (5) sejarah agraris. Sedangkan metode perancangan atau model visual ditegaskan oleh Laeyendecker (1991) bahwa, Model visual pada umumnya merupakan rekonstruksi kenyataan secara material dapat diraba seperti peta, dokumen dan gedung atau bangunan-bangunan lain. Dalam rangka menjelaskan struktur pabrik minyak kelapa, maka berikut ini adalah proses penelitian kualitatif dalam upaya mengungkap konstruksi realita dan nilai yang terkandung didalamnya melalui visual, Laeyendecker dalam Ratna, (2010: 285).

Desain penelitian ini dijabarkan dalam uraian unit kerja yaitu (1) Studi pendahuluan untuk mendapatkan pemetaan terhadap objek kajian. Dalam hal ini mapping terhadap sumber-sumber yang berkaitan dengan objek kajian. (2) Heuristik sebagai usaha pencarian dan menemukan sumber tertulis dan lisan terkait objek kajian. (3) Pra analisis dari hasil mapping dan heuristik. Selanjutnya, membuat kerangka referensi sebagai dasar menulis sejarah dengan langkahnya yaitu (1) Drafting Naskah sebagai bentuk penulisan awal dari hasil pengolahan data dan analisa. (2) Pemantapan Analisis lebih sebagai maksimalisasi hasil pengembangan data dan analisa dan (3) Penulisan. Luaran dari penelitian ini adalah buku ensiklopedia Pendidikan sejarah agraria suatu studi Pabrik Minyak Kelapa di Kebumen.

\section{PEMBAHASAN}

Penelitian ini telah dilakukan pada Mei hingga Agustus 2017, adapun proses pembahasan terbagi menjadi dua bagian yaitu hasil penelitian sejarah, dimana pada pembahasan ini lebih menitikberatkan kepada Intisari penelitian sejarah. Sedangkan pembahasan yang kedua adalah proses perancangan ensiklopedia sebagai media belajar sejarah. Berikut ini adalah hasil penelitian sejarah,

Wilayah Kebumen merupakan wilayah daerah pantai dan perbukitan, sedangkan sebagian besar merupakan dataran rendah. Sementara itu gambaran iklim tercatat curah hujan terbesar yakni $3.787,00 \mathrm{~mm}$ lebih tinggi dari tahun sebelumnya sebesar $2.328,43 \mathrm{~mm}$ dan hari hujan sebanyak 188 hari lebih sering dari tahun sebelumnya sebanyak 108 hari. Suhu terendah yang terpantau di stasiun pemantauan Wadaslintang pada bulan Juli dengan suhu sekitar $20,60^{\circ} \mathrm{C}$ dan tertinggi $34,00^{\circ} \mathrm{C}$ pada bulan Maret. Rata-rata kelembaban udara setahun $81,00 \%$ dan rata-rata kecepatan angin 0,23 meter/detik. Sedangkan pada stasiun pemantauan Sempor suhu terendah $21,60^{\circ} \mathrm{C}$ terjadi pada bulan Agustus dan tertinggi $33,60^{\circ} \mathrm{C}$ pada bulan Februari. Rata-rata kelembaban udara setahun $84,00 \%$ dan rata-rata kecepatan angin $1,99 \quad$ meter/detik, (http://www.kebumenkab.go.id/).

Berdasarkan keadaan geografis dan iklim yang demikian, wilayah Kebumen memiliki kemampuan untuk membangun sektor ekonominya dengan bertumpu pada sektor agraria. Dataran rendah yang cukup luas, serta ditopang dengan curah hujan dan sumber air yang berasal dari sungai, membuat Kebumen menjadi salah satu lumbung padi di Jawa Tengah. Hal tersebut sudah mampu dibuktikan sejak masa-masa Kerajaan Islam berkusa di tanah Jawa. Dalam sebuah sumber dijelaskan bahwa pada masa penguasaan 
Panembahan Senopati, wilayah Panjer (nama awal wilayah Kebumen) merupakan wilayah yang terkenal sebagai lumbung pangan/ padi. Berbekal kemampuan dan modal keadaan alam yang mampu untuk membangun struktur ekonomi berbasis agraria tersebut, maka tidaklah mengherankan jika wilayah Kebumen secara umum diisi oleh penduduk yang mayoritas berprofesi sebagai petani (hal ini merupakan pola umum yang terdapat diwilayah pedalaman Jawa). Kelompok para petani Kebumen memiliki peran yang cukup besar pada masa Perang Diponegoro, karena segala kebutuhan perbekalan perang yang dibutuhkan oleh pasukan Pangeran Diponegoro, dalam bentuk persedian pangan dan senjata disediakan oleh masyarakat Panjer. Seperti masyarakat Jawa lainnya (khususnya wilayah Jawa Tengah yang berada dibawah penguasaan Kerajaan), formasi sosial masyarakat Kebumen memiliki kemiripan dengan wilayah-wilayah lainnya. Struktur sosial dibangun atas dasar masyarakat feodal, dimana Raja (Sultan) menguasai daerah tersebut, yang diwakili oleh keberadaan individu yang ditunjuk langsung oleh Sultan (Carey, 2011:716).

Selanjutnya, pasar internasional pada akhir abad ke-17 menunjukkan perubahan permintaan dalam hal jenis komoditi perdagangan, dimana gejala tersebut terwujud dalam bentuk penurunan permintaan terhadap komoditi rempah-rempah. Penurunan dan perubahan permintaan terhadap komoditi rempah-rempah, bukan hanya terjadi karena over produksi komoditi rempahrempah, akan tetapi juga dikarenakan munculnya beberapa komoditi perdagangan yang menjadi primadona baru, yakni gula, teh, kopi, dan kopra. Permintaan terhadap barang-barang komoditi yang disebutkan sebelumnya di pasar internasional, penguasa lokal dan pemerintah kolonial Hindia-Belanda menambah jumlah areal lahan penananman dan mobilisasi tenaga kerja secara masif (Winoto, 1904:8-9; Rucinawati, 2001:5). Berkaitan dengan penelitian ini mengenai tanaman kelapa dan industri minyak kelapa di Kebumen, pelaksanaan dan pembangunan industri minyak kepala sama sekali berbeda dengan tanaman tebu dan teh.

Masyarakat Kebumen tidak lagi harus mempelajari bagaimana menanam dan membudidayakan tanaman kelapa, karena masyarakat Kebumen sudah cukup lama mengenal tanaman kelapa beserta fungsi-fungsinya. Berdasarkan keberadaan gambar relief tanaman kelapa yang berada di Candi Borobudur, maka tanaman kelapa sudah dikenal oleh penduduk Jawa sejak abad IX Masehi. Berdasarkan sumber yang lain, pada masa Islam menyebar luas di tanah Jawa, para Bupati dan tokoh ulama bermufakat agar calon pengantin pria membawa tunas/cikal bakal tanaman kelapa sebagai ongkos nikah kepada penghulu, meskipun tidak dijelaskan alasannya akan tetapi kebijakan tersebut tetap dijalankan hingga tahun 1890. Pohon kelapa yang diberikan oleh para calon penganti tersebut, kemudian dibagi-bagikan kepada penduduk untuk ditanam. Kebijakan lainnya yang diterapkan oleh pemerintah kolonial dalam menghidup-kan usaha penanaman kelapa di Jawa ialah dengan mengeluarkan kebijakan pelarangan penebangan pohon-pohon kelapa yang dianggap masih produktif. Surat keputusan tersebut dikeluarkan oleh Gubernur Jendral Rochsussen, dimana surat tersebut melarang pohon kelapa digunakan untuk pembuatan pekerjaan umum seperti jembatan dan proyek lainnya(Oliegewassen dan Van Gorkom, 1913:194-195).

Menurut sumber lainnya, tanaman kelapa yang berada di Jawa hingga pada tahun 1851 kira-kira berjumlah 9 juta 
pohon, dan pada tahun 1872 mencapai 2 juta pohon. Maksimalisasi penanaman pohon kelapa di Jawa hingga awal abad ke-20, sejatinya berjalan dalam model pengelolaan secara tradisional. Secara umum dapat dijelaskan sebagai berikut : buah kelapa yang dijadikan bibit diambil dari pohon kelapa yang berbuah lebat. Buah yang dibutuhkan ialah yang bentuknya besar dan bentuknya bulat. Dengan menggunakan model "gantung" dan diletakkan diatas tanah yang lembab, persemaian terhadap bibit kelapa ini dilakukan. Berkaitan dengan pemupukan bibit kelapa, petani kelapa di Jawa, biasanya menggunakan campuran garam dan abu untuk menyuburkan dan mendapatkan hasil yang baik.

Bahwa Perkembangan paling awal yang terjadi pada medio awal abad ke-20 berkaitan dengan pengusahaan minyak kelapa di Kebumen dan di Jawa secara umum ialah munculnya industrialisasi dan korporatisasi dalam industri minyak kelapa. Hal ini memberikan konsekuensi berupa pembentukan sistem dan mekanisme kerja yang rasional dan terencana dari proses pengolahan minyak kelapa di Kebumen. Proses korporatisasi ini mengubah secara mendasar sifat dan karakter dari industri pengolahan minyak kelapa di Kebumen, dari yang semula bersifat pemenuhan kebutuhan seharihari menjadi pemenuhan kebutuhan bersufat massal. Hal ini dapat terjadi karena sejak menjelang berakhirnya abad ke-19, komoditi kopra beserta minyak kelapa sudah mulai masuk kedalam jaringan pasar internasional, dan menjadi semakin kokoh pada periode awal abad ke-20. Perkembangan pengolahan minyak kelapa menjadi bercirikan korporasi, juga berdampak kepada pengenalan masyarakat petani di Kebumen kepada sistem moneter (keuangan), dimana hal ini secara umum memang fenomena yang seragam dengan model-model industri dalam jenis-jenis komoditi lainnya, akan tetapi tetap memberikan pola yang unik dan berbeda dengan model lainnya. Industrialisasi dan korporatisasi pengolahan minyak kelapa di Kebumen, sangat didukung oleh faktor investasi dan modal, maka sudah menjadi sebuah keniscayaan jika fenomena monetisasi industri minyak kelapa menjadi satu hal yang umum terjadi di awal abad ke-20.

Perkembangan lanjutan, beserta dampak dari masuknya pabrik minyak kelapa langsung dalam aktivitas produksi di Kebumen, berupa pengolahan minyak kelapa dengan dua model yakni pengolahan secara tradisional dan modern. Keberadaan pabrik minyak kelapa di Kebumen NV. Mexolie Keboemen, sejak tahun 1923 tidak hanya memberikan perkembangan dan dampak yang dirasakan dalam sektor sosial dan ekonomi (berupa penyerapan tenaga kerja dan komersialisasi tanaman kelapa), lebih dari itu dampak lain juga dirsakan dalam aspek geografis. Semakin pesat dan berkembangnya industri minyak kelapa di Kebumen, memberikan konsekuensi berupa pembukaan lahan yang lebih luas (areal tanam) pohon kelapa. Hal ini dilakukan untuk dapat mengimbangi antara proses produksi dengan permintaan dan penawaran dari pasar minyak kelapa.

Berkaitan dengan partisipasi dan respon masyarakat Kebumen terhadap keberadaan pabrik minyak kelapa $N V$. Oliefabrieken Insulinde, tidak didapatkan data yang valid mengenai derajat partisipasi masyarakat lokal Kebumen. Hal ini tidaklah mengeherankan karena tanaman kelapa sejatinya merupakan sumber bahan mentah bagi petani untuk menghasilkan barang-barang yang dikonsumsi bagi kebutuhan hidup seharihari, dengan kata lain belum memiliki nilai komersil yang tinggi. Menurut Rucinawati (2001: 9-11), barang-barang komoditi tersebut diantaranya ialah 
minyak klentik, kethak yang dapat dikonsumsi, ampasnya yang dapat digunakan sebagai makanan babi, serabut kelapa digunakan sebagai alat pembersih dan batok kelapa biasanya digunakan sebagai alat mengambil air dan menjadi arang untuk memasak dan membuat makanan.

Kesadaran dan pengetahuan tentang nilai komersil yang termuat dalam tanaman kelapa dan keberadaan teknologi yang masih tradisional dapat menjadi jawaban mengapa kelompok petani di Kebumen belum dapat berpartisipasi dan terlibat secara aktif dalam proses produksi minyak kelapa di pabrik minyak kelapa $N V$. Oliefabrieken Insulinde. Berkaitan dengan kelompok yang cukup aktif dalam proses produksi minyak kelapa sebelum masuk kedalam parik minyak kelapa $N V$. Oliefabrieken Insulinde. menurut sumber yang didapat, kelompok saudagar/pedagang Cina dan Arab adalah kelompok yang sangat aktif dalam menampung kelapa dan mendistribusikan ke pabrik minyak kelapa $N V$. Oliefabrieken Insulinde (Rucinawati, 2001: .15). Keadaan tersebut juga tidak terlalu mengherankan, karena kelompok pedagang Cina dan Arab memang dikenal memiliki jaringan dagang dan posisi tawar dalam aktivitas ekonomi di Hindia Belanda hingga akhir era penguasaan kolonial Belanda.

Keberadaan pabrik minyak kelapa di Kebumen NV. Mexolie Keboemen, sejak tahun 1923 tidak hanya memberikan perkembangan dan dampak yang dirasakan dalam sektor sosial dan ekonomi (berupa penyerapan tenaga kerja dan komersialisasi tanaman kelapa), lebih dari itu dampak lain juga dirsakan dalam aspek geografis. Semakin pesat dan berkembangnya industri minyak kelapa di Kebumen, memberikan konsekuensi berupa pembukaan lahan yang lebih luas (areal tanam) pohon kelapa. Hal ini dilakukan untuk dapat mengimbangi antara proses produksi dengan permintaan dan penawaran dari pasar minyak kelapa. Mengenai data yang valid tentang berapa areal tanam awal dan perubahannya hingga akhir pemerintahan kolonial Hindia-Belanda, memang tidak didapatkan, akan tetapi melihat angka konsumsi dan ekspor minyak kelapa dari Jawa yang selalu meningkat (Surat Kabar "Het Nieuws van Den Dag Voor Nederlansch-Indie", 17 April 1915), maka dapat dipastikan bahwa terjadi hubungan antara luas areal tanam dengan peningkatan jumlah produksi.

Berikut adalah suatu proses perancangan buku ensiklopedia pabrik minyak kelapa di Kebumen,

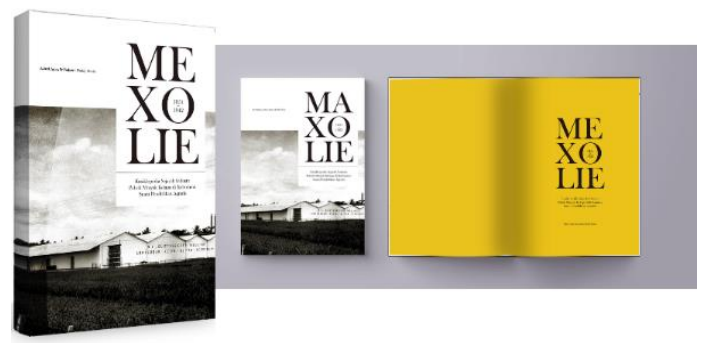

Gambar 1

Desain Sampul Ensiklopedia Pabrik Mexolie di Kebumen

(Dokumen Peneliti)

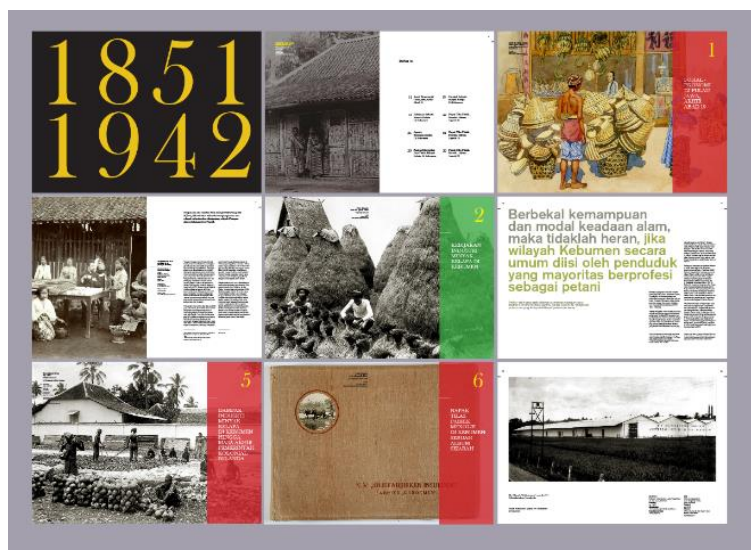

Gambar 2

Desain Layout Ensiklopedia Pabrik Mexolie di Kebumen

(Dokumen Peneliti) 


\section{PENUTUP}

Pembahasan sejarah mengenai industri minyak kelapa di Kebumen pada masa pemerintahan kolonial HindiaBelanda, menjadi satu bahasan yang cukup menarik. Hal ini bukan saja karena kajian sejarah yang mencoba menangkap dinamika masyarakat Kebumen pada masa kolonial, khususnya yang berkaitan dengan kehidupan ekonomi petani Kebumen yang dapat dikatakan masih langka. Kajian ini menjadi semakin menarik karena dapat menyingkap tentang bagaimana sesunguhnya proses adaptasi kelompok petani dalam perubahan-perubahan yang terjadi di Kebumen. Kajian ini dapat menjadi satu bahan rujukan disaat tinjauan tentang sejarah ekonomi di Kebumen yang cukup langka, dan diharapkan akan semakin banyak lagi dimasa yang akan datang berkaitan dengan kajian sejarah ekonomi masyarakat Kebumen. Penyajian buku ensiklopedia seperti ini paling tidak telah memberikan suatu gagasan yang dapat diterapkan untuk terus mengeksplorasi media belajar sejarah dimasa datang.

\section{DAFTAR PUSTAKA}

Arsip

Collectie tropen museum Kabinetcirculaire, 1850 No. 14 (ANRI: Bijbl. 216)

\section{Buku}

Amri, A. (2013). Model Penelitian Desain Komunikasi Visual. PT. Cipta Caraka Nusantara: Jakarta

Asba, R. (2007). Kopra Makassar: Perebutan Pusat dan Daerah, sebuah Kajian Sejarah Ekonomi Politik. Yayasan Obor Indonesia. Jakarta.
Boeke J.H. dan Burger. (1973). Ekonomi Dualistik : Dialog Antara Boeke dan Burger. Bharatara. Jakarta.

Denzin, N.K. dan Lincoln, Y.S.. (2009). Handbook Of Qualitative Research, Yogyakarta: Pustaka Pelajar.

Furnivall, J.S. (2009). Hindia Belanda: Studi Tentang Ekonomi Majemuk. Freedom Instute. Jakarta

Glasgow, D. (1994). Information Illustration, Addison-Wesley Publishing Company.

Kartodirdjo, S. (1992). Pendekatan Ilmu Sosial dalam Metodologi Sejarah. Gramedia. Jakarta.

Kuntowijoyo. (2003). Metodologi Sejarah. Tiara Wacana. Yogyakarta.

Margana, S. dan Fitria, W. (2010). Sejarah Indonesia: Perspektif Lokal dan Global, persembahan 70 tahun Prof. Dr. Djoko Suryo. Ombak. Yogyakarta

Marihandono, D. (2008). Titik Balik Historiografi Indonesia. Wedatama Widya Sastra. Jakarta.

Padmo, S. (2004). Bunga Rampai Sejarah Sosial-ekonomi Indonesia. Aditya Media. Yogyakarta

Ratna, N. K. (2010). Metodologi Penelitian Kajian Budaya dan Ilmu Sosial Humaniora Pada Umumnya. Yogyakarta: Pustaka Pelajar.

Sachari, A. (2002). Estetika: Makna, Simbol dan Daya. Bandung: Penerbit ITB 
Walker, John A.. (2010). Desain, Sejarah, Budaya, Yogyakarta: Jalasutra,

Wicandra, O. B. (2001). Skripsi, Memahami Wacana Infografis: Sebuah Kajian Semiotik dengan Kasus Infografis pada Seksi Deteksi Harian Jawa Pos Edisi Bulan Februari-Bulan Oktober 2000, Yogyakarta: Institut Seni Indonesia.

\section{Publikasi Lainnya}

Paper Kerja oleh Yayasan Wahyu Pancasila, dipublikasikan di seminar keluarga besar eks karyawan Pabrik Minyak Kelapa Kebumen, pada 31 Mei 2015

\section{Arsip Dokumen Resmi}

Album met foto's van de fabriek
'Keboemen'
Oliefabrieken

http://collectie.tropenmuseum.nl/ default.aspx?lang=en\& ga $=2.22$ $\underline{0609240.1118668004 .150427811}$ 0-1716576087.1504278110, diakses Juli-Agustus 2017.

\section{Dokumen Karya Desain}

Cover Design: Poster Design 2015 by Quim Marin, https://id.pinterest.com/behance/

Layout Design : fiverr.com

www.id.pinterest.com/source/fiverr.com

Layout Design : Behance

www.id.pinterest.com/source/behance

Font Baskerville Old Face by Isaac Moore Trademark of Stephenson Blake (Holdings) Ltd, www.microsoft.com/typography/ fonts/font.aspx?FMID=919 